\title{
Implementation of vector control on electric vehicle traction system
}

\author{
Nady Ibrahim*, Mohamed Abdelaziz, Maged Ghoneima and Sherif Hammad
}

\begin{abstract}
Background: Nowadays, electric vehicle development takes a great attention in vehicle industry and researches, due to demising supplies of fuel, less pollution, and developing many resources of generating electricity as renewable energy and clean resources.

Results: This research is a part of the Autotronics Research Lab (ARL), applying researches on autonomous and electric vehicles. The main aim of the research is to apply vector control method on traction control system of electric vehicle (mini golf cart) by using two hub motors on the rear wheels while the two front wheels are used for steering; it is assumed that the controlled vehicle is fitted with some equipment which can used in autonomous driving. Simulation results show the output response of speed and torque of the vehicle motors and vehicle speed while the vehicle is moving in a straight line or during steering and also show the fusion between vector control and power steering algorithm.
\end{abstract}

Conclusions: The system preforms the efficiency, safety, accuracy, and more controllability of electric vehicle traction system, leading to more stability in vehicle speed, lower troubleshoots, and less error in unstable surfaces and bad roads.

Keywords: Electric vehicle (EV), Induction motors (IM), Indirect vector control, Traction system, Power steering system, Ackermann-Jeantnat model

\section{Background}

The main idea that will be discussed in this research is the implementation of vector control system technology on traction system (electronic power steering, acceleration and deceleration by using regenerative torque) to ensure reliability and efficiency of the controlled vehicle.

The performance of the controlled EV traction system shown in Fig. 1 depends on many parameters such as stability in curves and off roads, acceleration time, low troubleshoots and stability in vehicle speed and motor speed output signal while steering takes place.

The system design applied indirect vector control on the two rear induction hub motors (Gang et al, 2012) and discussed the fusion of vector control model with Ackermann-Jeantnat model of steering kinematics, trying to perform output speed of vehicle during acceleration, deceleration, and steering while accelerating or decelerating either in good roads or unstable surface; this shows the system necessity.

\footnotetext{
* Correspondence: Eng.NadyEmad@gmail.com

Faculty of Engineering, Ain Shams University, Cairo, Egypt
}

Integration of accelerator pedal, brakes, and steering wheel takes place as the main controller of the SIMUlink model computing required motor speed signals as an input to the vector control model which controls vehicle motors; simulations take place for many different cases of vehicle traction system.

\section{Methods \\ Motor sizing Vehicle parameters}

The research is applied on EV; this section will explain how to calculate the motor torque required for the desired $\mathrm{EV}$, and there are many parameters needed for motor sizing calculations (Chauhan, 2015) and all other calculations needed. All parameters are shown in Table 1.

\section{Calculations required for motor torque}

Factors affecting vehicle torque: 

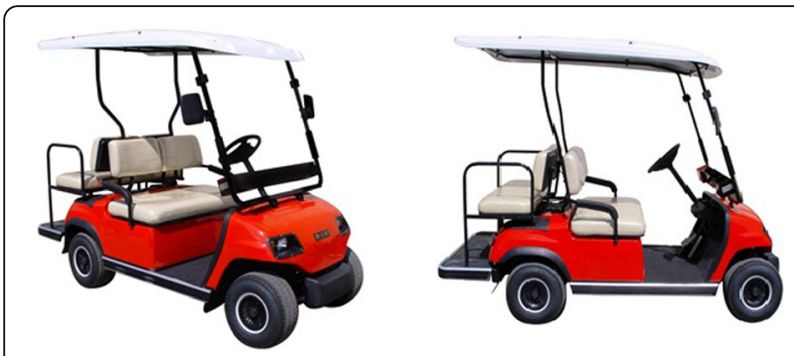

Fig. 1 Two-wheel drive vehicle

1. Rolling resistance (RR), which is the opposing resistance at which the vehicle must overcome during rolling motion

2. Grad resistance (GR), which is the force responsible for pulling up the vehicle to an inclined surface

3. Acceleration force (FA)

where:

$$
\begin{aligned}
& R R=G W \times C r, \\
& \text { i.e., } \mathrm{GW}=217 \mathrm{~kg} \mathrm{~ms}^{-2} \\
& G R=G W \times \sin (\theta) \\
& \mathrm{FA}=\mathrm{m} \times \mathrm{a},
\end{aligned}
$$

where (a) is the required acc.

$$
\begin{aligned}
& m=\mathrm{GW} / \mathrm{g}, \\
& \text { i.e., } \mathrm{g}=9.81 \mathrm{~m} / \mathrm{s}^{2}
\end{aligned}
$$

Total tractive effort (TE) is the sum of total forces required to make the vehicle move forward, and it is a very important parameter in calculating required the motor torque where:

Table 1 Vehicle parameters, symbols, and quantities

\begin{tabular}{ll}
\hline Parameter & Symbol and quantity \\
\hline Length & $L=1.25 \mathrm{~m}$ \\
Width & $W=0.65 \mathrm{~m}$ \\
Mass of vehicle & $\mathrm{M}=22.15 \mathrm{~kg}$ \\
Gross vehicle weight & $\mathrm{GW}=217 \mathrm{~kg} \mathrm{~ms}^{-2}$ \\
Co-efficient of rolling resistance & $\mathrm{Cr}=0.017$ for fair asphalt \\
& $\mathrm{Cr}=0.060$ for firm sand \\
Total tractive effort & $\mathrm{TE}$ \\
Fractional losses & $\mathrm{R}_{\mathrm{f}}$ \\
Body moment of inertia & $J$ \\
Tire radius & $R$ \\
Steering angle & $\delta$ \\
Acceleration due to gravity & $g=9.81 \mathrm{~m} / \mathrm{s}^{2}$ \\
Inclination angle & $\Theta<,=15^{\circ}$ \\
Desired rotor flux & $\psi^{*}{ }_{\mathrm{r}}=0.85$ \\
\hline
\end{tabular}

$$
\mathrm{TE}=\mathrm{RR}+\mathrm{GR}+\mathrm{FA}
$$

Therefore, the motor torque $(\mathrm{Tm})$ required for the desired vehicle is:

$\mathrm{Tm}=\left(\mathrm{TE} \times \mathrm{R}_{\mathrm{f}} \times \mathrm{r}\right) / 2$, i.e., this is the torque required for each motor

\section{Vector control or field-oriented control (FOC)}

The two main types of vector control are direct vector control and indirect vector control. This section will discuss about using indirect vector control and its implementation on EV traction system.

The vector control provides superior dynamic performance for AC machines and brushless DC motors where FOC operates motors softly and balanced over full speed ranges without high troubleshoots; also, FOC operates the motors with optimum stable torque, and FOC has very important characteristics for EV. It generates full torque at zero speed and fast acceleration and deceleration for controlled motors, giving high performance for EV. Figure 2 presents the FOC in the electrical traction chain.

\section{Theory of operation}

FOC is a closed loop system which identifies three phase components of stator currents as two components orthogonal on each other, this is done by Park and Clark transformations (Q\&D transformation) (Husien \& Bazaz, 2015), and these components are represented as flux and torque components similar to the two components of the DC motors (armature flux $I_{\mathrm{a}}$ and field flux $I_{\mathrm{f}}$ )

where $I_{\mathrm{ds}}$ (induction motor) $\equiv I_{\mathrm{f}}$ (DC motor)

and $I_{\mathrm{qs}}$ (induction motor) $\equiv I_{\mathrm{a}}$ (DC motor)

where $I_{\mathrm{ds}}$ is the flux component and $I_{\mathrm{qs}}$ is the torque component, and controlling two decoupled vectors is more easier, giving high dynamic response. FOC calculates $I_{\mathrm{ds}}$ and $I_{\mathrm{qs}}$ by Q\&D transformation, and $I_{\mathrm{ds}}$ and $I_{\mathrm{qs}}$ are part of the calculating rotor angle $\theta_{\mathrm{r}}$ which entered in negative $\mathrm{Q} \& \mathrm{D}$ transformation.

The calculation of $\mathbf{i}^{*}$ qs is through the desired torque value $\left(\mathrm{T}_{\mathrm{e}}^{*}\right)$ which is the output of PI controller that tunes the reference speed with the actual speed, $\mathbf{i}^{*}{ }_{d s}$ is calculated through the desired value of the rotor flux $\left(\Psi_{\mathrm{r}}\right.$ *), then the two desired components are transformed to three-phase desired components $\mathrm{Ia}^{*}, \mathrm{Ib}^{*}$, and $\mathrm{Ic}^{*}$ by negative Q\&D transformation as shown in Fig. 4 (Ramesh et al, 2015), and comparing these components to the actual three phase current components Ia, Ib, and Ic by current regulator (hysteresis band), the output of the hysteresis band pluses are controlling the inverter. 
Fig. 2 Basic electrical traction chain

\section{Indirect vector control}

The main difference between indirect vector control and direct vector control is the computation method of electrical rotor angle and number of sensors used, where the indirect vector control can be called sensorless vector control.

Indirect vector control calculates the rotor angle by using rotor position measurements and machine parameter estimation (Gasbaoui et al., 2011), where the rotor angle $\theta_{\mathrm{r}}$ is calculated by the integration of the sum of rotor mechanical speed $\mathrm{GO}_{\mathrm{r}}$ and calculated slip speed $\mathrm{GO}_{\mathrm{r}}{ }^{*}$ as shown in Fig. 3, i.e., it allows high performance control of speed and torque and rotor position of the controlled motor.

Reasons for using indirect vector control over direct vector control:

- Sensors are eliminated causing decreasing coast factor

- Does not directly involve flux estimation

- Less sensitive to parameters variation

- Higher dynamic performance

- There are no drift problems such as indirect FOC

\section{Electrical rotor angle computation $\left(\theta_{r}\right)$}

$$
\begin{aligned}
& \theta_{\mathrm{r}}=\int\left(\omega_{\mathrm{r}}+\omega_{\mathrm{r}}^{*}\right) \cdot \text { the main equation } \\
& \omega_{\mathrm{r}} \times(\mathrm{rad} / \mathrm{s})=\mathrm{L}_{\mathrm{m}} * \mathrm{i}_{\mathrm{q}} /\left(\mathrm{T}_{\mathrm{r}} * \psi_{\mathrm{r}}\right) \\
& \mathrm{T}_{\mathrm{r}}(\mathrm{s})=\mathrm{L}_{\mathrm{r}} / \mathrm{R}_{\mathrm{r}} \\
& \mathrm{L}_{\mathrm{r}}(\mathrm{mH})=\mathrm{L}_{\mathrm{m}}+\mathrm{L}^{\prime}{ }_{\mathrm{r}} \\
& \Psi_{\mathrm{r}}=\mathrm{L}_{\mathrm{m}} \times \mathrm{i}_{\mathrm{d}} /\left(1+\mathrm{T}_{\mathrm{r}}\right)
\end{aligned}
$$

where $\mathrm{GO}_{\mathrm{r}}$ and $\mathrm{GO}_{\mathrm{r}}{ }^{*}$ are in $\mathrm{rad} / \mathrm{s}, \mathrm{T}_{\mathrm{r}}$ is the rotor time constant, $\mathrm{R}_{\mathrm{r}}$ is the rotor resistance $=0.236 \mathrm{ohms}, \mathrm{L}_{\mathrm{r}}, \mathrm{L}_{\mathrm{m}}$, and $\mathrm{Ll}_{\mathrm{r}}$, are the coils from the equivalent circuit of the induction motor, and $\Psi_{\mathrm{r}}$ is the calculated rotor flux.

$$
\begin{aligned}
& I^{*}{ }_{q s} \text { and } I^{*}{ }_{d s} \text { computation } \\
& \mathrm{I} * \mathrm{ds}=\psi_{\mathrm{r}} * / \mathrm{L}_{\mathrm{m}} \\
& \mathrm{I}{ }^{*} \mathrm{q}=(2 / 3) \times(2 / \mathrm{p}) \times\left(\mathrm{L}_{\mathrm{r}} / \mathrm{L}_{\mathrm{m}}\right) \times\left(\mathrm{Te} * / \psi_{\mathrm{r}}\right)
\end{aligned}
$$

where $p$ is the number of poles and $\mathrm{T}_{\mathrm{e}}{ }^{*}$ is desired torque required.

The FOC method completes out calculations of the needed required torque for the controlled machine. It controls the inverter through the hysteresis controller which compares each current line with its reference value, and the result is six pulses control the universal inverter, as Fig. 4 shows the final and detailed block diagram of the indirect vector control applied in the software model integrated with steering model, induction motor, universal inverter, and hysteresis current regulator.

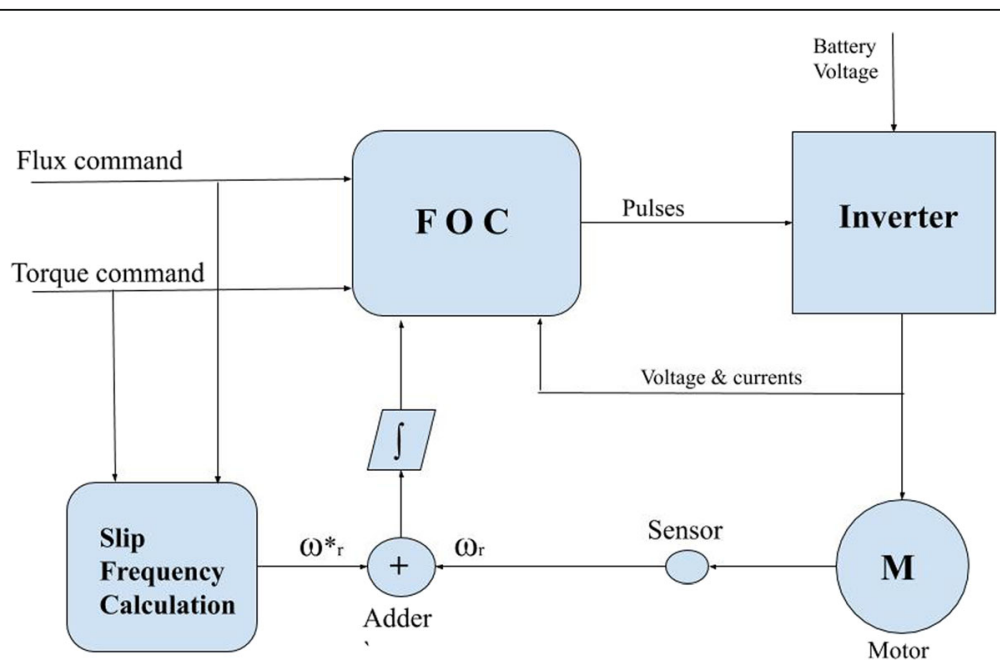

Fig. 3 Indirect vector control block diagram 


\section{Traction system}

\section{Accelerator pedal}

This section discusses the fusion of the accelerator pedal and power steering and brake pedal with the FOC, where the traction system expressed in power steering, accelerator pedal, and brake pedal is combined together in the model as one dynamic controller in which its output feeds the two vector controllers with the required speed signals to control the two motor speeds according to the position of the accelerator pedal and steering angle.

The accelerator pedal is the main item responsible for the acceleration and deceleration for the vehicle. The accelerator pedal has a direct connection with the vector control while the steering angle is equal to zero; each position on the accelerator pedal indicates a specific required speed signal, tuning the FOC to the required speed, and this position is indicated by sensors such as potentiometer.

The length of the accelerator pedal used in the project is $10 \mathrm{~cm}$. This indicates that when the position of the pedal is at the lowest level at $0 \mathrm{~cm}$, the speed of the motors will be zero, and when the position on highest level at $10 \mathrm{~cm}$, the speeds of the motors could reach the motor rated speed, so it can be indicated as the following:

$$
\begin{aligned}
\text { Speed signal }= & \text { pedal position } \times \frac{\text { motor rated speed }}{\text { pedal length }} \\
& \times \frac{\pi}{30} \text { output is in } \mathrm{rad} / \mathrm{s}
\end{aligned}
$$

where the speed signal is the input signal to the FOC to operate the motors at this required speed. While the steering angle is equal to zero, the velocity of the two motors is equal to each other; although if the new speed signal is higher than that of the last one, this means that the FOC passes higher positive torque to the motors to accelerate and reach the new speed and accelerate the vehicle, and if the new signal is lower than that of the last one, this means that the FOC passes negative torque for the motors to decelerate and decelerate the vehicle.

\section{Analysis of power steering system kinematics}

The fusion of power steering system with vector control in my model is by the Ackermann-Jeantnat model (Zhai \& Dong, 2011) of steering run for low speed vehicle mode as shown in Fig. 5 where the two front wheels are responsible for steering with angle $\delta$ and the two rear wheels are responsible for driving the vehicle equipped with two independent hub motors.

The basic idea of the model is to compute the speeds of the two rear wheels during steering; $V_{\mathrm{rr}}$ and $V_{\mathrm{rl}}$ are expressed as the following:

$$
\begin{aligned}
& \mathrm{V}_{\mathrm{rr}=\mathrm{V}}\left(1+\mathrm{W} \times \tan \left(\frac{\delta}{2 \times \mathrm{L}}\right)\right) \\
& \mathrm{V}_{\mathrm{r} 1=\mathrm{V}}\left(1-\mathrm{W} \times \tan \left(\frac{\delta}{2 \times \mathrm{L}}\right)\right)
\end{aligned}
$$

where $V_{\text {rr }}$ is velocity of the rear right motor, $\mathrm{V}_{\mathrm{rl}}$ is the velocity of the rear left motor, $\mathrm{V}$ is the vehicle speed computed according to the position of the accelerator pedal, and $\delta$ is the steering angle, and according to Eqs. (12) and (13), the speed of the driving wheels are variables in $V$ and $\delta$ and changes with their changing, and during steering to any direction, the outer motor speed is higher than the inner one, where the AckermannJeantnat model expresses the kinematic relation between the inner and the outer wheels during steering.

The steering angle $\delta$ indicates the trajectory direction of the vehicle where $\delta<0$ turn left, $\delta>0$ turn right, and $\delta=0$ moving in straight line.

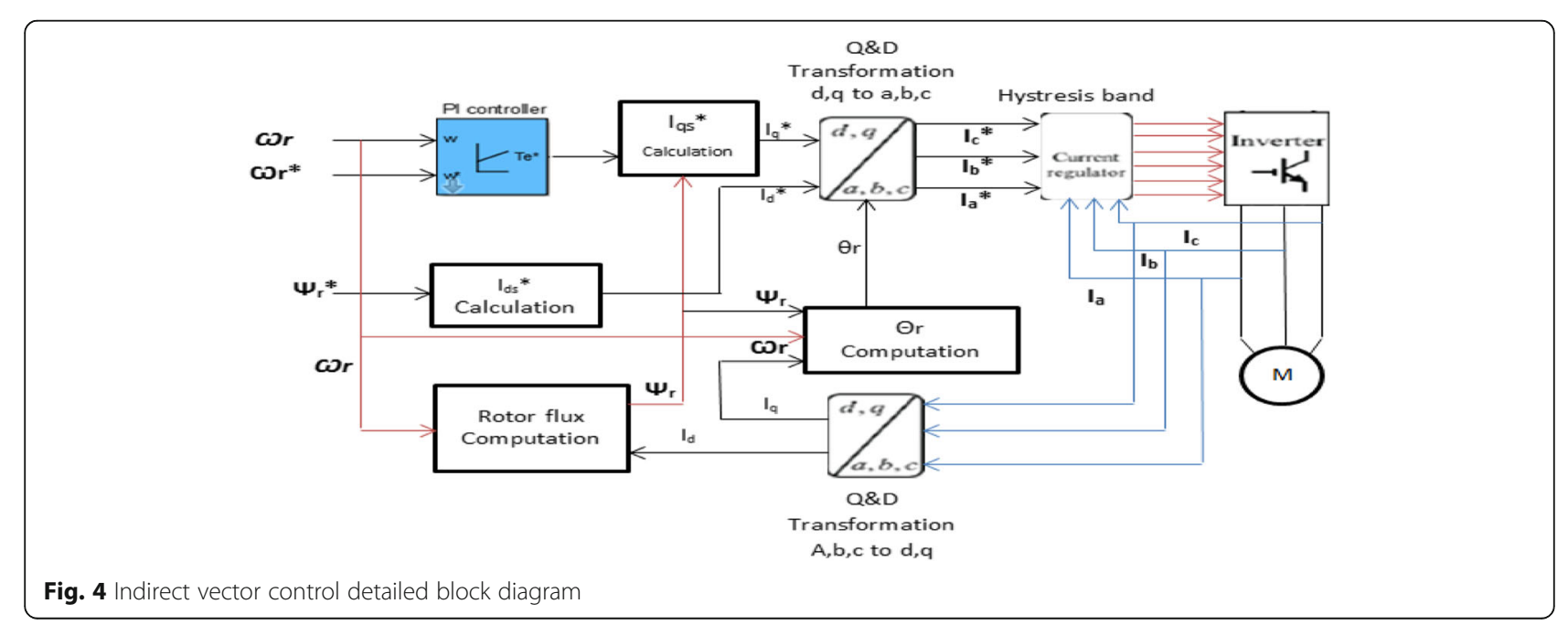




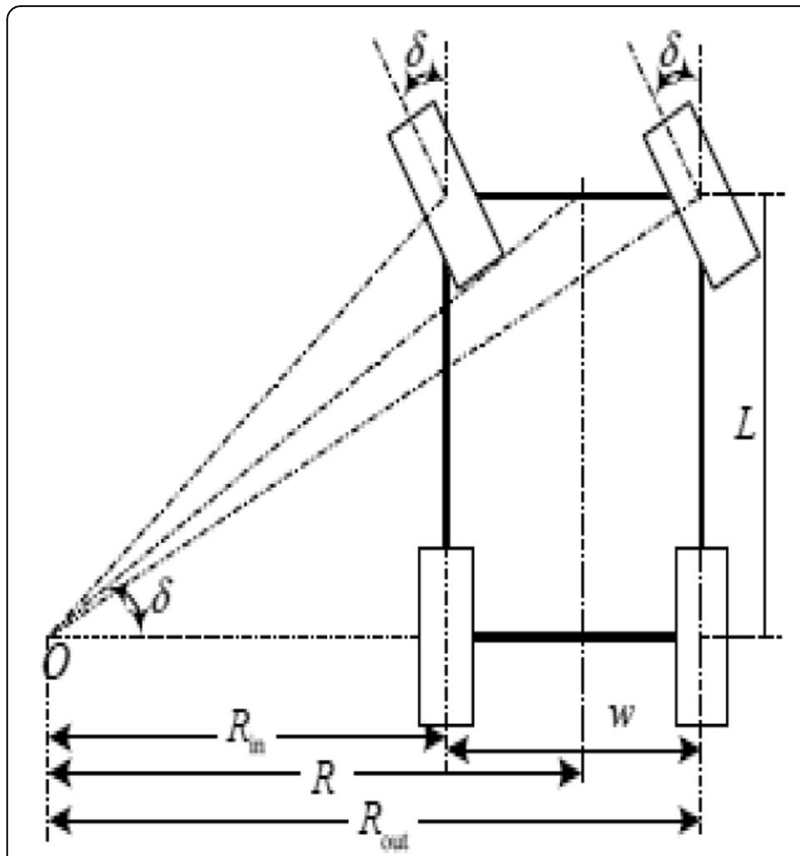

Fig. 5 The Ackermann-Jeantnat model and brake signal are defined as the main controller of the system, and the main controller output is the input speed signal of the FOC controller during steering and while moving in straight line as presented in Fig. 6.

\section{Six DOF dynamic electric vehicle models}

The dynamic electric vehicle models are simplified as shown in Fig. 7. There are six degrees of freedom. They are expressed as four degrees of the four wheels' rotational motion, and the other two DOF are expressed as the longitudinal motion and lateral motion of the controlled mobile vehicle (Doumati et al, 2010). This research model is expressed in low speeds of motion where the front right wheel angle is equal to that of the front left wheel angle, $\delta_{\mathrm{fr}}=\delta_{\mathrm{fl}}$ $=\delta$.

Longitudinal equation of motion:

$\mathrm{V}_{x}^{\prime}=\frac{1}{\mathrm{~m}}\left[\left(\mathrm{~F}_{\mathrm{xfl}}+\mathrm{F}_{\mathrm{xfr}}\right) \times \cos \delta-\left(\mathrm{F}_{\mathrm{yfl}}+\mathrm{F}_{\mathrm{yfr}}\right) \times \sin \delta+\mathrm{F}_{\mathrm{xrl}}+\mathrm{F}_{\mathrm{xrr}}\right]$

Lateral equation of motion:

$$
\mathrm{V}_{\mathrm{y}}^{\prime}=\frac{1}{\mathrm{~m}}\left[\left(\mathrm{~F}_{\mathrm{yfl}}+\mathrm{F}_{\mathrm{yfr}}\right) \times \cos \delta+\left(\mathrm{F}_{\mathrm{xfl}}+\mathrm{F}_{\mathrm{xfr}}\right) \times \sin \delta+\mathrm{F}_{\mathrm{yrl}}+\mathrm{F}_{\mathrm{yrr}}\right]
$$
of the vehicle is directly proportional to the velocities of the driving wheels according to the Ackermann model, i.e., the output signals of the Ackermann model modeled with accelerator pedal where $F_{x f l}, F_{x f r}, F_{x r l}$, and $F_{x r r}$ are the longitudinal forces affecting on the four wheels (front-left and front-right

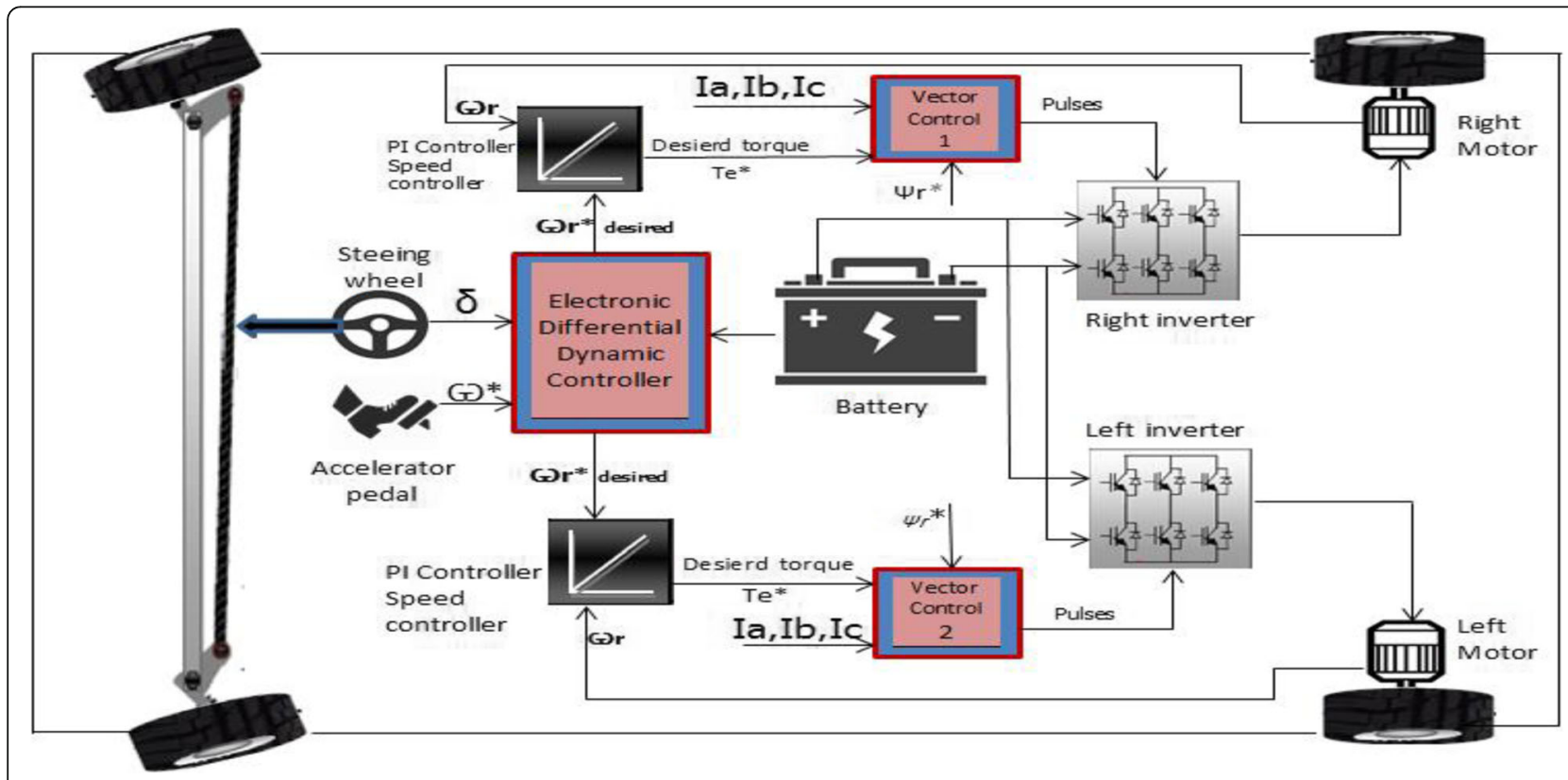

Fig. 6 Driving and steering wheel control system 


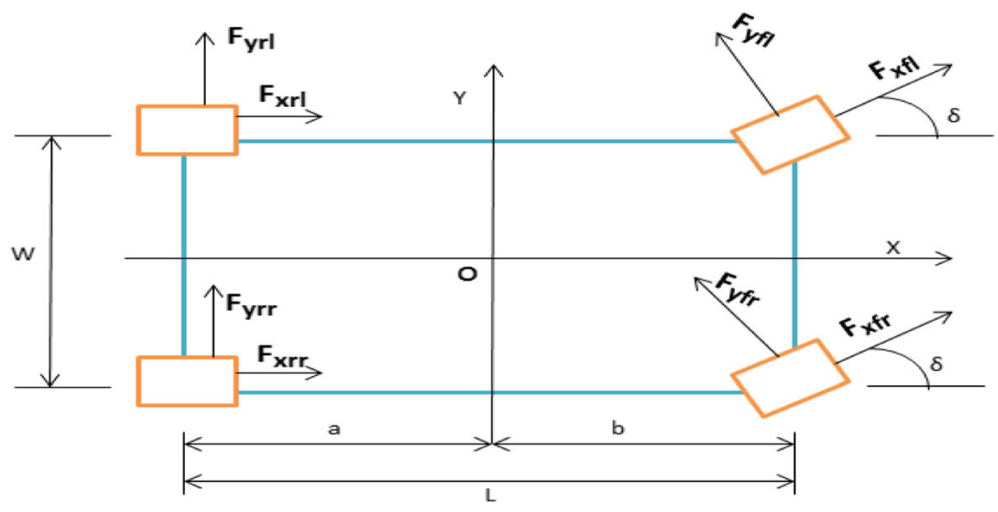

Fig. 7 Two independent driving wheel models

and rear-left and rear-right); also, $F_{y f f}, F_{y f r}, F_{y r b}$ and $F_{y r r}$ are the lateral forces affecting on the four wheels.

\section{Results}

This section explains many cases of the controlled vehicle under many different conditions illustrating the output results of the Simulink model showing the output of the motor speed and torque, vehicle speed, and speed commands.

\section{First case}

This case shows the response of the two motors when the vehicle is moving in straight line in a smooth way applying acceleration and deceleration to the vehicle through the accelerator pedal, where the starting mode is from zero with highest torque. As shown in Fig. 8, the speed starts from zero with acceleration, then the motor acts as a brake (regenerative torque) decelerating the vehicle then accelerating again, then moving with constant speed, then decelerating with negative torque, and finally moving in constant speed, where the output of the two motors are the same due to the steering angle being equal to zero $(\delta$ $=0)$. The first figure shows the speed command and motor speed (RPM), the second figure shows the electromagnetic torque and output torque of the motors $(\mathrm{Nm})$, and the third one shows the line current $[\mathrm{A}]$.

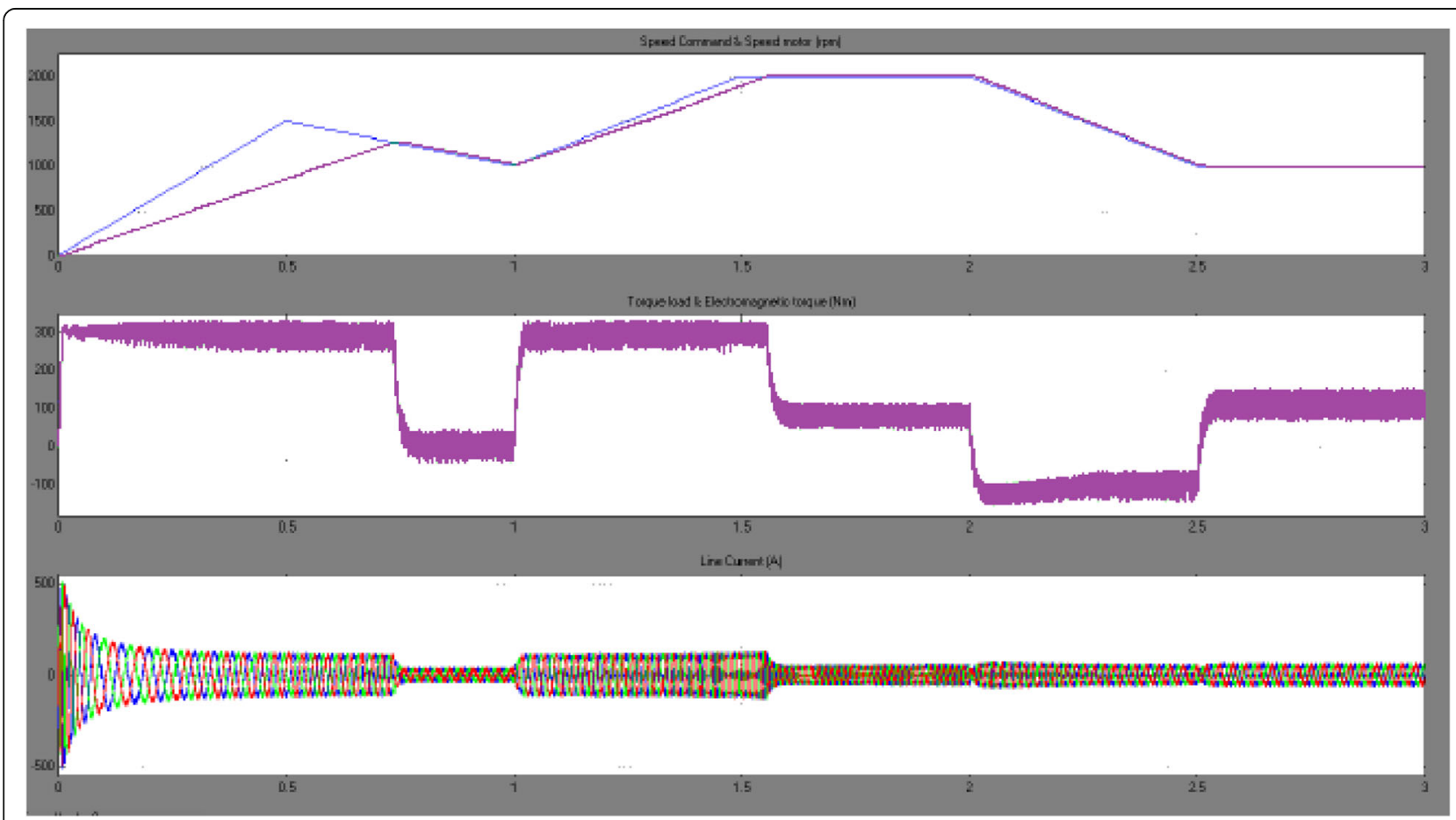

Fig. 8 Speed command, actual motor speed, currents, and torque 


\section{Second case}

This case shows the output response of the vehicle and the motors' command and speeds while the vehicle is moving in straight line from zero and then accelerating at $(T)<2$ and moving with constant speed at $2<(T)<4.5$ and then applying steering angle to the left at $\delta=20$ and moving with constant speed at $(T)>4.5$; the results in this case shows the output of the vehicle speed $(\mathrm{rad} / \mathrm{s})$ and the difference between the speed of the two motors during steering $(\mathrm{rad} / \mathrm{s})$.
The first figure (Fig 9a) shows the difference between the speed commands of the two motors, the second figure (Fig. 9b) shows the difference between the left motor speed and command $(\mathrm{rad} / \mathrm{s})$, the third figure (Fig. 9c) shows the difference between the right motor speed and command, and the fourth figure (Fig. 9d) shows the vehicle speed.

\section{Third case}

This case shows the output response of the vehicle speed and motors speed and command while the

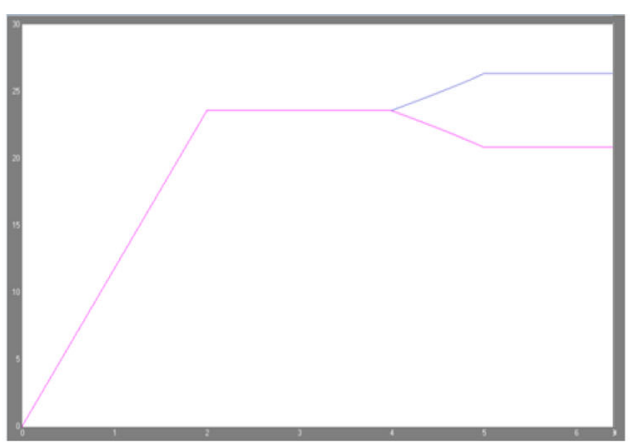

(a) speed Command signals of the two motors $\mathrm{rad} / \mathrm{sec}$

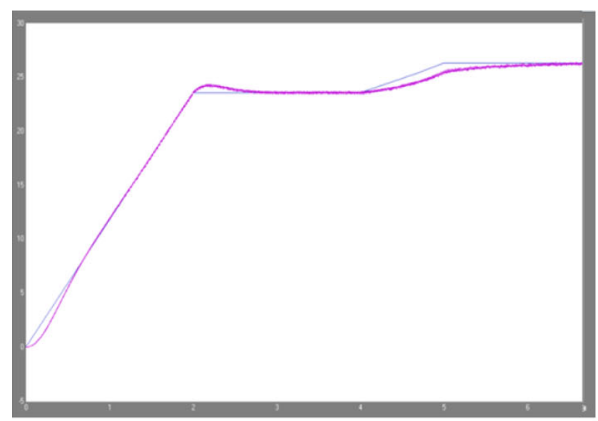

(b) left motor output speed and command signa $\mathrm{rad} / \mathrm{sec}$

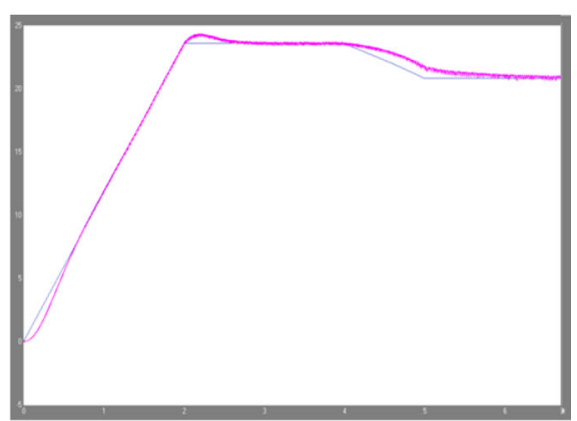

(c) right motor output speed and command signal $\mathrm{rad} / \mathrm{sec}$

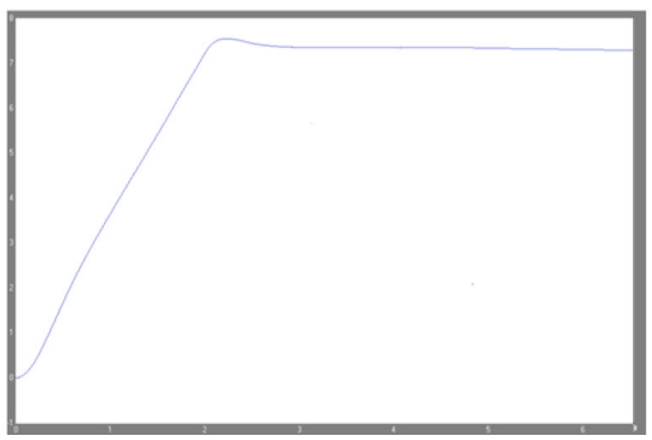

(d) Vehicle speed $\mathrm{m} / \mathrm{sec}$

Fig. 9 a Speed command signals of the two motors (rad/s). b Vehicle speed (rad/s). c Right motor output speed and command signal (rad/s). d Vehicle speed $(\mathrm{m} / \mathrm{s})$ 
vehicle is moving in straight line in a rough road as firm a sandy road, at time $(T)>3 \mathrm{~s}$, then turned right with angle $\delta=0$ to $\delta=-15$ from $T=3.5 \mathrm{~s}$ to $t=5$ $\mathrm{s}$, then steering with constant speed; at $7<T<8 \mathrm{~s}$, the vehicle is accelerating while steering take place with $\delta=-15$, and finally at $T>8 \mathrm{~s}$, the vehicle is rotating with angle $\delta=-15$ with higher constant speed Fig. 10.

\section{Discussion}

The simulation results discuss the main idea and aim of the research, at which it shows the implementation of indirect vector control on the vehicle traction system under many different cases as accelerating and decelerating by using accelerator pedal, using steering wheel during constant speed and using steering wheel during acceleration.

The results shows good symmetry between the speed command and actual speed of motors either in case two for good roads or in case three for unstable roads and also shows the constant speed of electric vehicle during steering with different angles either in the second or in third case.

The system has some limitations: first, the Ackermann-Jeantnat model is used for low speeds of vehicles giving higher troubleshoots for high speeds; second, the inclination angle for inclined surfaces is limited at $\Theta<,=15^{\circ}$; and third, the brakes are applied as a signal only in the software model to stop controlling of FOC on the motors and not applied as a brake model.

\section{Conclusion}

The research has focused on the feasibility, accuracy, and stability of the real EV traction system integrated with vector control of two rear hub motors.

This research showed up the fusion between indirect vector control applied on two rear independent driving

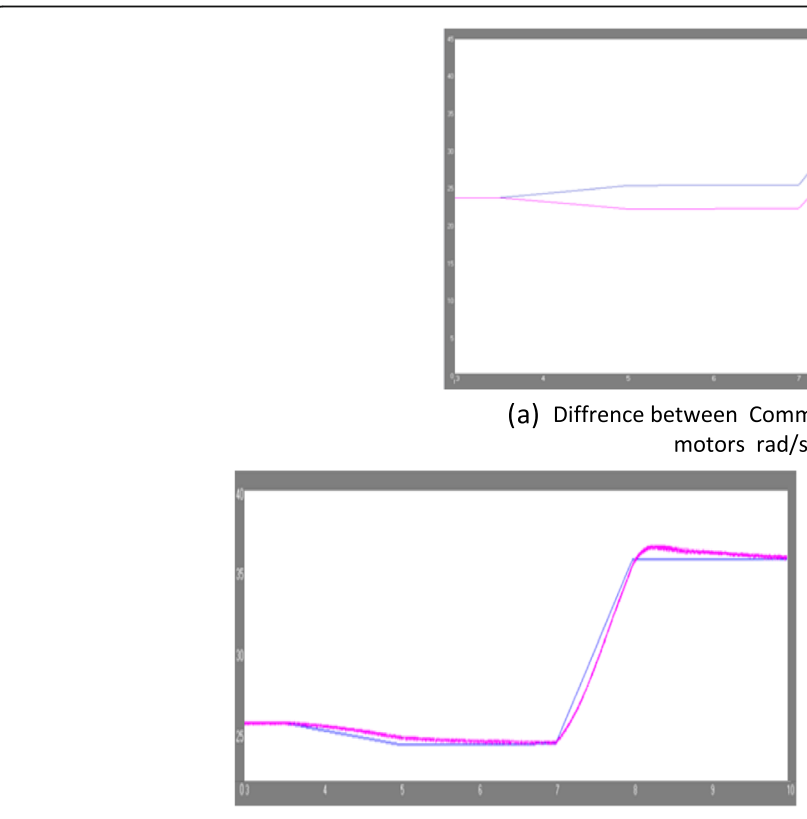

(b) left motor output speed and speed comand signal rad/sec

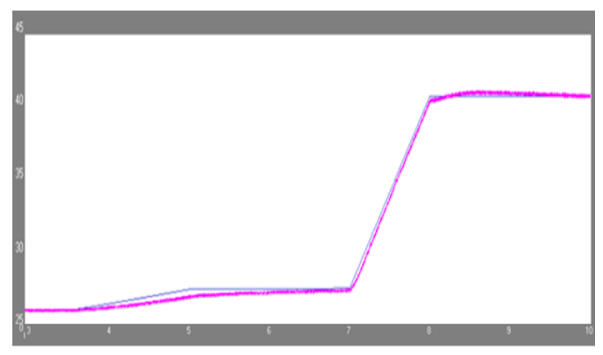

(c) Right motor output speed and speed comand signal rad/sec

(d) Vehicle speed $\mathrm{m} / \mathrm{sec}$

Fig. 10 a Difference between command speed signal of two motors (rad/s). b Left motor output speed and speed command signal (rad/s). c Right motor output speed and speed command signal (rad/s). d Vehicle speed $(\mathrm{m} / \mathrm{s})$ 
wheels and Ackermann-Jeantnat model for power steering, the combination between vehicle traction system models expressed in accelerator pedal model, and the power steering model and brakes are the main controller of the vehicle which feeds the indirect vector control with the required input speed signal.

The indirect vector control models improve the driving wheel speeds with high accuracy in curved roads, straight roads, and inclined roads and also provide optimization and perfection of vehicle speed and motion during acceleration and deceleration, giving low troubleshoot percentage of $\pm 1.5 \%$, and using regenerative torque in decelerating the vehicle speed will help in selfrecharging of the battery and increase its life time.

Using this criteria of controllers improves the controllability of the independent driving wheels leading to optimum torque commands and lower troubleshoots in unstable surfaces giving high performance for the traction system overall.

Motor control strategies and properties can affect vehicular steering properties directly; therefore, the two hub motors' independent driving vehicle should be attached with high speed controller properties.

\footnotetext{
Abbreviations

ARL: Autotronics Research Lab; Cr: Co-efficient of rolling resistance; DOF: Degree of Freedom; EV: Electric vehicle; FA: Acceleration force; Fig.: Figure; FOC: Vector control or field; $F_{x f l}$ : Longitudinal force affecting front-left wheel; $F_{\text {xfr: }}$ Longitudinal force affecting front-right wheel; $F_{x r}$ : Longitudinal force affecting rear-left wheel; $F_{x r r}$ : Longitudinal force

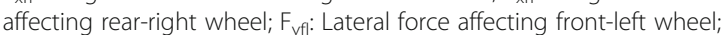
$F_{\text {yfr: }}$ Lateral force affecting front-right; $F_{\text {yr: }}$ Lateral force affecting rear-left; $F_{y r r}$ Lateral force affecting rear-right; g: Acceleration due to gravity; GR: Grad resistance; GW: Gross vehicle weight; $i^{*}{ }_{\text {ds: }}$ Flux desired value; $i^{*}{ }_{\text {qs: }}$ Torque desired values; la: DC motor armature flux; $I_{d s}$ : Induction motor flux component; If: DC motor field flux; IM: Induction motor; Ias: Induction motor torque component; L: Length; M: Vehicle mass; p: Number of poles; Q\&D transformation: Park and Clark transformations; RR: Rolling resistance; $\mathrm{R}_{\mathrm{r}}$ : Rotor resistance; T: Time; TE: Total tractive effort; $\mathrm{T}_{\mathrm{e}}{ }^{*}$ : Desired torque value; Tm: Motor torque; $T_{r}$ : Rotor time constant; $\mathrm{V}$ : Vehicle velocity; $\mathrm{V}_{\mathrm{r}}$ : Velocity of the rear left motor; $V_{r r}$ : Velocity of the rear right motor; w: Width; $\delta$ : Steering angle; $\Theta$ : Inclination angle; $\theta_{r}$ : Rotor angle; $\psi_{r}^{*}$ : Desired rotor flux;

$\psi_{r}:$ Calculated rotor flux; $\omega_{r}$ : Rotor mechanical speed; $\omega_{r}^{*}$ : Calculated slip speed
}

\section{Acknowledgements}

The research is supported by the Ain Shams University \& ARL team. I would to thank Prof. Hussain Faried \& Dr. Mohammad Soliman where they belongs to the Faculty of Engineering at the Ain Shams University for their practical participation, advices, and input in my research; also, I must express my very profound gratitude to my parents and my wife for providing me with unfailing support and encouragement.

\section{Authors' contributions}

MA contributed in the SIMU link model, system modeling, and Autotronics System overall. MG and SH contributed in the software programming and sensor fusion for all the ARL team. All authors read and approved the final manuscript.

\section{Funding}

All funding are divided between the Ain Shams University and the ARL team.

\section{Availability of data and materials}

The datasets used and analyzed during the current study are available from the corresponding author on reasonable request.

Ethics approval and consent to participate

Not applicable

\section{Consent for publication}

The corresponding author is an official postgraduate student of the Ain Shams University, and after registration of the research point, the author has the rights to publish his research paper to complete the master's degree.

\section{Competing interests}

Not applicable

Received: 9 August 2019 Accepted: 16 December 2019

Published online: 07 February 2020

\section{References}

Chauhan S (2015) Motor torque calculations for electric vehicle. International Journal of Scientific \& Technology Research 4(8)

Doumati M, Victorino A, Charara A, Lechner D (2010) A method to estimate lateral tire force and the sideslip angle of a vehicle: experimental validation. American Control Conference June 30 - July 02

Gang L, Wei H, Daming Z, Changfu Z (2012) Research on control strategies of two independent rear wheels drive electric vehicle, International Conference on Applied Physics and Industrial Engineering

Gasbaoui B, Chaker A, Laoufi A (2011) The efficiency of direct torque control for electric vehicle behavior improvement. Serbian Journal of Electrical Engineering 8(2)

Husien S, Bazaz MA (2015) Review of vector control strategies for three phase induction motor drive. International Conference on Recent Developments in Control, Automation and Power Engineering

Ramesh K, RaviKumar CH, Bala MP (2015) Modeling and implementation of vector control for induction motor drive. International Journal of Engineering Research and General Science 3(2)

Zhai L, Dong S (2011) Electronic differential speed steering control for four inwheel motors independent drive vehicle. World congress on Intelligent Control and Automation June

\section{Publisher's Note}

Springer Nature remains neutral with regard to jurisdictional claims in published maps and institutional affiliations.

\section{Submit your manuscript to a SpringerOpen ${ }^{\circ}$ journal and benefit from:}

- Convenient online submission

- Rigorous peer review

- Open access: articles freely available online

High visibility within the field

- Retaining the copyright to your article

Submit your next manuscript at $\boldsymbol{\nabla}$ springeropen.com 